\title{
Displacement analysis of surrounding rock deformation of Baochang tunnel in Yunnan
}

\author{
Lianghan Zhang ${ }^{1}$, Xiaolong $\mathrm{Li}^{1}$, Xinyun $\mathrm{Ma}^{1}$, Hongyan $\mathrm{Guo}^{2 *}$ and ${\mathrm{Ke} \mathrm{Li}^{2}}^{2}$ \\ ${ }^{1}$ Shidian Baoshi Expressway Investment and Development Co., Ltd, Baoshan, 678000, China; \\ ${ }^{2}$ China Merchants Chongqing Communications Technology Research \& Design Institute Co., Ltd, Chongqing,400000, China
}

\begin{abstract}
According to the problem of deformation of surrounding rock when the double-wall method is adopted in the tunnel, the five tunnel monitoring points are set in the tunnel vault, arch waist and arch foot to simulate the tunnel excavation process. The surrounding rock is deformed, and the excavation of the middle guide hole makes the deformation of the surrounding rock reach $7.2 \mathrm{~mm}$. After the removal of the middle partition wall, the deformation reaches the maximum, which is $8.4 \mathrm{~mm}$. The horizontal displacement starts to increase rapidly, and the maximum is $5.3 \mathrm{~mm}$. According to the analysis results, the surrounding rock above the tunnel should be reinforced in time, and the deformation of the surrounding rock after the removal of the middle partition wall should be paid attention to ensure the construction safety and provide reference for future construction.
\end{abstract}

\section{Introduction}

Due to the continuous disturbance of the rock mass during the excavation process, the double-wall method requires the surrounding rock to settle again. It is necessary to monitor the settlement variation of the surrounding rock during the construction process to ensure that the displacement meets the requirements during the construction process. Therefore, it is important to analyze the vertical settlement and horizontal displacement during the excavation process of the double-wall method, which can guide the key monitoring points during the construction process and ensure the construction safety. [1-3].

Domestic and foreign scholars have used the theory and numerical simulation to do the following research on the influence of tunnel excavation on the buildings above the tunnel: Zou Chong et al. used Midas software to analyze the Chongqing Track 5 line, and obtained the double-wall guide pit method. The top position of the arch is subject to large force and low stability, and the displacement of the middle partition wall is abruptly changed [4]. Based on the Chongqing rail change line, Cui Zhendong concluded that the double-slab method should be used to reinforce the middle wall rock pillars before excavation to improve the tunnel stress and convergence deformation [5].

Based on the example of the Baochang tunnel, the numerical simulation method is used to analyze the displacement deformation during the construction process of the double-wall construction method. By comparing the vertical settlement and horizontal displacement of the surrounding rock, the settlement and the settlement of the double-wall method are obtained.
Key construction procedures provide research support for construction safety and control of surrounding rock deformation [6-10].

\section{General situation of Engineering}

The starting tunnel of the maintenance tunnel is $\mathrm{K} 23+540 \sim \mathrm{K} 24+360$, the length is $820 \mathrm{~m}$, the depth is $95.59 \mathrm{~m}$, the left hole is ZK23+541.43 ZK24+445, the length is $903.57 \mathrm{~m}$, the short tunnel is buried, the depth is $100.97 \mathrm{~m}$. The tunnel has a clear distance of $15 \sim 17 \mathrm{~m}$ and the cross section is a separate tunnel, as shown in Figure 1 . The elevation of the tunnel area is $1545 \sim 1643 \mathrm{~m}$, and the relative height difference is $97 \mathrm{~m}$. It belongs to the dissolution and erosion low mountain landscape. The terrain is steep. The tunnel entrance has rural dirt road access and convenient transportation. The entrance section is lush, the exit section is mountainous, and the vegetation is less developed.

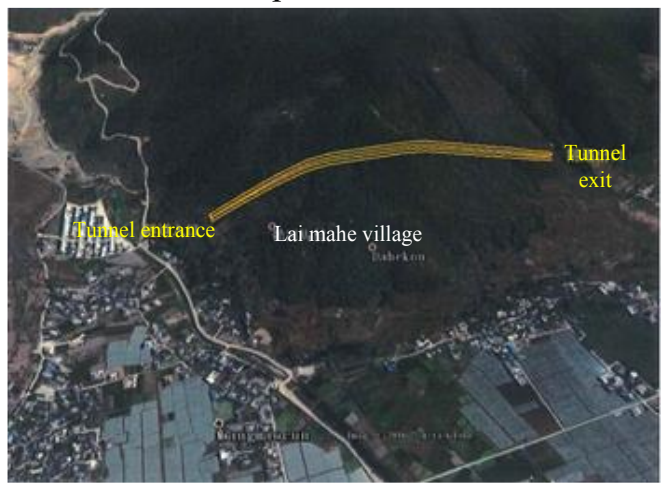

Figure 1. Topography of Re Baochang Tunnel

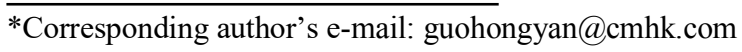




\subsection{Engineering geological conditions.}

According to the regional geological data of Yunnan Province, the area where the line is located is located in the composite part of the Yunnan-type mountain front structure and the middle branch of the eastern branch of the Qinghai-Tibet-Burma-type structure system. The geological structure is complex in the area, and the tectonic geological structure is the backbone structure. The long-term activity of the zonal structure, the meridional structure is a prominent structural system in the area, which belongs to the meridional tectonic system of the Sichuan-Yunnan system, mainly consisting of the compressive, torsional fracture and small amount of the same direction of the meridional tectonic system.

The tunnel crossing the medical stratum is dominated by the Silurian upper system (S3) and the Devonian upper system (D1) marl, which is a dissolution and erosion low-mountain landform. From the structure, the tunnel mountain is a single oblique mountain; A dome mountain, the sides of the hole are convex slopes, which is conducive to the drainage of the hole and the stability of the slope. The mountain shape is full and full, indicating that the rock mass is good. The slope of the entrance section is gentle, the natural slope is $20 \sim 30^{\circ}$; the exit section is slow, the natural slope is $15 \sim 25^{\circ}$, and the terrain is more undulating.

\subsection{Hydrogeology}

The project area is located in the Nujiang River system, and the area where the tunnel is located is in the Shidian River Basin. There is no surface water body on the tunnel mountain. The entrance side of the river is located at the bottom of the valley of Hema Village. There is a large amount of water. The upstream is building a reservoir to intercept the water. The current water level is far lower than the tunnel design elevation, and there is no ground for the supply tunnel.

\section{Numerical simulation analysis}

\subsection{Parameter selection}

This paper uses FLAC3d to numerically simulate it, as shown in Figure 2. In the simulation process, the surrounding rock adopts the hexahedral element, the Mohr-Coulomb constitutive model, the support adopts the shell model, and the second lining adopts the line model.

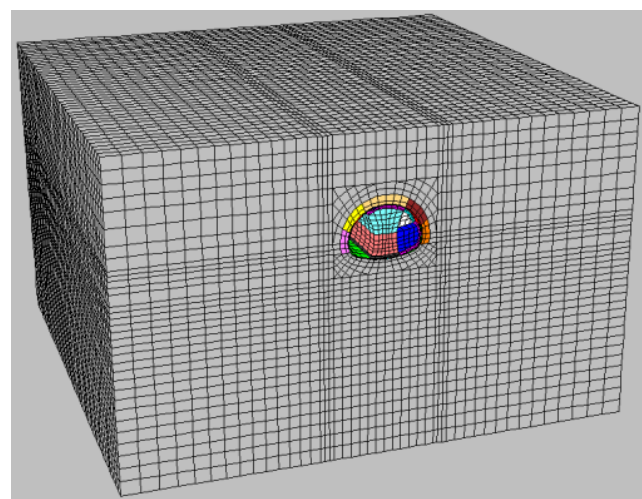

Figure 2. Calculation model diagram

The surrounding rock and support parameters are shown in Table 1.

Table 1. Mechanical parameters of surrounding rock and support

\begin{tabular}{ccccc}
\hline $\begin{array}{c}\text { Rock and } \\
\text { soil }\end{array}$ & $\begin{array}{c}\text { Density } \\
(\mathrm{g} / \mathrm{cm} 3)\end{array}$ & $\begin{array}{c}\text { Bearing } \\
\text { capacity of } \\
\text { foundation } \\
(\mathrm{kPa})\end{array}$ & $\begin{array}{l}\text { friction } \\
\varphi^{(}\end{array}$ & $\begin{array}{c}\text { Cohesion } \\
(\mathrm{MPa})\end{array}$ \\
\hline Silty clay & 18 & 230 & 13.4 & 0.04 \\
\hline
\end{tabular}

\subsection{Monitoring point arrangement}

By setting 3 settlement points on the left, middle and right guide arches of the tunnel vault, two horizontal displacement monitoring points are set on the side wall of the side wall guide pit, as shown in Figure 3. Through these five monitoring points, the overall settlement and horizontal convergence of the tunnel during the tunnel excavation process are obtained.

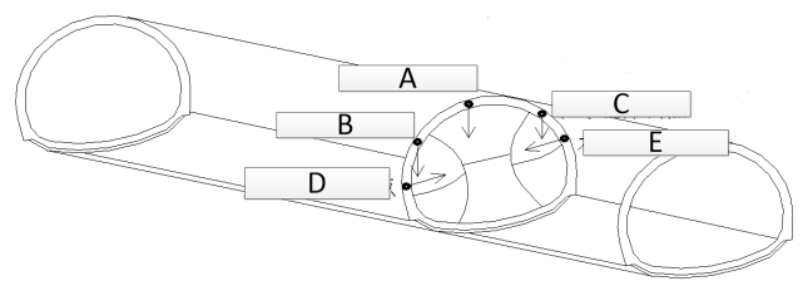

Figure 3. Monitoring point location

\subsection{Analysis of results}

During the tunnel excavation process, the arch settlement curve is shown in Figure 4. It can be seen that the displacement of the dome changes rapidly at the beginning, and the surrounding rock is disturbed again due to the excavation of the soil in the right and middle guide pits, so that the settlement of the middle guide pit is the largest, reaching $7.2 \mathrm{~mm}$; After the wall is removed, the temporary support disappears, causing the arch settlement to increase again, up to $8.4 \mathrm{~mm}$. 


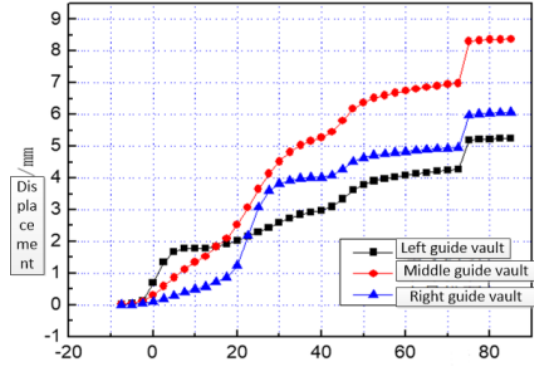

Distance from the face

Figure 4. Vertical displacement distribution of surrounding rock

During the tunnel excavation process, the horizontal displacement of the surrounding rock is shown in Figure 5. The excavation of the left, middle and right guide holes caused the horizontal displacement to increase rapidly at the beginning, mainly due to the unloading of the surrounding rock and the deformation of the surrounding rock around the tunnel. As the surrounding rock gradually stabilized and the supporting structure was applied in time, the horizontal displacement gradually stabilized. Its maximum horizontal displacement is $5.3 \mathrm{~mm}$.

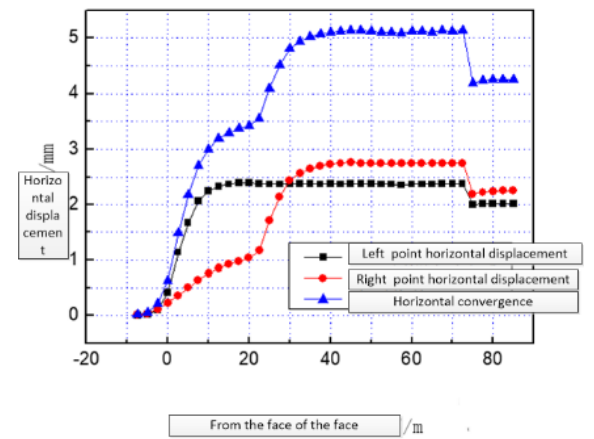

Figure 5. Horizontal displacement map of surrounding rock

In summary, when using the double-wall method, the deformation will occur during the excavation process and the temporary support demolition process. Therefore, the initial support should be applied in time to strengthen the monitoring and measurement of the monitoring points to ensure construction safety.

\section{Conclusion}

Through the comprehensive analysis of the guaranteed tunnel, the influence of surrounding rock deformation during the construction of the two-lane tunnel using the double-wall method is studied. Through the numerical simulation of the excavation section, the following conclusions are drawn:

(1) The amount of explosives should be strictly controlled during the construction of tunnel blasting excavation, and the possibility of damage to the top of the building caused by blasting vibration should be considered.

(2) The tunnel is a short tunnel. Due to the fracture of the rock mass and the requirements of the construction period, the distance between the two working faces should be strictly controlled to avoid the superposition effect of the two-hole stress release ring.

\section{Acknowledgments}

The authors would like to express their appreciation to the National Natural Science Foundation of China (41601574), the Chongqing Basic and Frontier Research Project (cstc2015jcyjBX0118), the Chongqing Science and Technology Innovation Leading Talent Support Program (CSTCCXLJRC201715), and the Chongqing Social Undertakings and Livelihood Security Science and Technology Innovation and Special Program (cstc2017shmsA30010) for providing funding for this research.

\section{Reference}

1. Wang D.Y., Yuan J.X., Zhu Y.Q., Liu J., Wang H.F. (2019) Model test study on deformation characteristics and reasonable reserve deformation of hard plastic-flow-plastic shallow-buried loess tunnel[J/OL]. Rock and Soil Mechanics, (10): 1-10[2019-05-03].

2. Du H.X., Sun W., Xu S., Liu B.H. (2019) Study on Mechanical Characteristics and Deformation Control of Initial Support Bearing of Super Large Cross Section Tunnel Based on ABAQUS Arch Model[J]. Journal of Highway and Transportation Research and Technology,15(03) ): 130-132.

3. Huang Z.D. (2019) Research on deformation mechanism of rock formation and tunnel excavation[J]. Journal of Highway and Transportation Technology (Apps \& Technology Edition), 15 (03): 133-136.

4. Zou W., Jin X.L., Gao X.J., Hu Y.B., Liang B. (2017) Optimization of Excavation Steps in Double-Wall Guide Pit Method for Super Large Cross-section Tunnels[J]. Journal of Henan University of Science \& Technology (Natural Science),38(04):66-71+119-120.

5. Cui Z.D. (2017) Stability analysis and construction key technology of rock pillar excavation of large-section subway station in double-section guide pit construction[J]. Tunnel Construction, 37(09): 1140-1145.

6. Feng H.J., Yu R.G. (2019) Numerical analysis of the influence of shield tunneling on ground settlement in a double-track tunnel[J]. Journal of Railway Engineering Society, (03): 78-83.

7. Guo J., Yang J.S., Chen W., Shen D., Liu T., Chai W.Y. (2019) Study on the characteristics of large deformation and lining of surrounding rock in carbonaceous slate tunnel based on field measurement[J]. Chinese Journal of Rock Mechanics and Engineering, 38 (04): 832-841.

8. Deng W., Shi X.F., Yang G.L., Zhang H.Q. (2018) Numerical Modeling and Mechanical Analysis of Double Side Wall Guide Method for Large Cross-section Tunnels[J]. Highway, 63(03):253-259. 
9. Wang X.B. (2017) Application of Different Construction Methods in Large Deformation Control of Carbonaceous Schist Tunnel[J]. Tunnel Construction, 37(S1): 121-127.

10. Tian H., Xu P., Wu Y. (2016) Study on deformation characteristics of large-section plateau loess tunnel support[J]. Highway Tunnel, (02): 8-11. 